Talía. Revista de estudios teatrales

ISSN-e: 2659-806X

\title{
Estrategias comunicativas en el teatro de Yolanda García Serrano
}

Juana N. Escabias ${ }^{1}$

Recibido: 19 de febrero de 2021 / Aceptado: 14 de marzo de 2021

Resumen: La dramaturga Yolanda García Serrano, Premio Nacional de Literatura Dramática 2018 por ; Corre! y Premio Lope de Vega 2013, es una desconocida para el universo de los estudios críticos, pese a haber publicado y estrenado cerca de cincuenta obras. En este artículo se compila su producción editada y llevada a escena, realizando un recorrido por la misma con objeto de poner en valor su trabajo como creadora y darlo a conocer. Se recogen también en él las estrategias comunicativas empleadas por la autora en su teatro, especialmente en su pieza ;Corre!, adentrándonos en el texto y el espectáculo al que sirvió de soporte.

Palabras clave: García Serrano; Teatro; Dramaturgas españolas.

\section{[en] Communication Strategies in Yolanda García Serrano’s Theater}

Abstract: The playwright Yolanda García Serrano, National Dramatic Literature Prize 2018 for ;Corre! and Lope de Vega Prize 2013, is a stranger to the universe of critical studies, despite having published and premiered nearly fifty works. This article compiles her edited and staged production, taking a tour of it in order to value her work as a creator and make it known. It also includes the communication strategies used by the author in her theater, especially in her piece ;Corre! Delving into the text and the show that served as support.

Keywords: García Serrano; Theater; Spanish playwrights.

Sumario. 1. La trayectoria dramática de Yolanda García Serrano. 2. Montajes en colaboración y piezas breves. 3. Cultivadora del género cómico. 4. El teatro editado de Yolanda García Serrano. 5. ¡Corre! Estrategias discursivas en el texto. 6. La eficacia comunicativa en la representación de ;Corre! Referencias bibliográficas.

Cómo citar: Escabias, J. N. (2021). Estrategias comunicativas en el teatro de Yolanda García Serrano, en Talía. Revista de estudios teatrales, 3, 125-133.

En el número 53 de la revista Las Puertas del Drama², Cristina Santolaria publicaba un artículo titulado Una dramaturga peculiar, polifacética y desconocida: Yolanda García Serrano. En él, manifestaba su estupefacción ante el hecho de que una autora con la trayectoria de Yolanda García Serrano pudiera haber pasado desapercibida para el universo de los estudios críticos, circunstancia que ella intentaba justificar achacándola a la extrema modestia con la que la dramaturga transitaba por el ecosistema teatral.

"Ignoro si esta actitud de García Serrano ha provocado que, en numerosos estudios sobre la dramaturgia española contemporánea, especialmente sobre la escrita por mujeres, su obra sea casi obviada y su nombre apenas figure en revisiones y antologías del periodo, cuando su andadura se remonta a la década de los 80" [Santolaria 2020].

Resulta sorprendente, en verdad, que una autora con el bagage de Yolanda García Serrano (Madrid, 1958), no figure en las antologías clásicas sobre teatro español contemporáneo. Tampoco aparece en las antologías dedicadas a las dramaturgas españolas contemporáneas vivas, ni en las referidas a mujeres que comenzaron a escribir teatro en España en la década de los ochenta ${ }^{3}$. Porque García Serrano comenzó a escribir teatro hace casi cuarenta años y también, aproximadamente en la misma época, a dirigir teatro. Es asimismo guionista de cine y televisión y directora de largos y cortometrajes. De hecho, fue la primera mujer guionista que obtuvo un Goya por el guion de la película Todos los hombres sois iguales, que escribió en

\footnotetext{
Este artículo se enmarca en los objetivos investigadores del ITEM y del proyecto CARTEMAD (H2019/HUM-5722).

Universidad Complutense de Madrid. ITEM - Instituto del Teatro de Madrid. jnescabias@ucm.es

Número 53 de Las Puertas del Drama, AAT, segundo semestre de 2020.

La única excepción a esta regla la constituye una breve referencia que aparece en el tomo III de Autoras en la Historia del Teatro Español (19752000), publicado por la ADE.
} 
colaboración con Joaquín Oristrell, Manuel Gómez Pereira y Juan Luis Iborra. Con el mismo trío de compañeros firmó los guiones de Salsa rosa (1991), ¿Por qué lo llaman amor cuando quieren decir sexo? (1992) y El amor perjudica seriamente la salud (1996) 4 . Además de esos títulos, ha colaborado en la escritura de los guiones de una docena de las películas más populares de la filmografía española de los últimos treinta años, como ¿De qué se ríen las mujeres? (1996) y Amor de hombre (1997), y escribió y dirigió en solitario los cortometrajes: "Si es usted una mujer maltratada, marque 1" (2003), "Catequesis" (2004), "Entrevista atravesada" (2011), "The actress" (2016) y "La novia tiene un sincope" (2017).

El medio televisivo tampoco es ajeno para ella, ha trabajado como guionista en numerosas series, entre ellas Cuéntame, Hit y Farmacia de guardia. También es adaptadora, y desde 1996 profesora intermitente en la Escuela de Cinematografía y del Audiovisual de Madrid (ECAM), en el Instituto del Cine de Madrid y en la Escuela Universitaria de Artes-TAI. Ha publicado asimismo tres novelas en solitario y dos en colaboración. En lo que al mundo teatral se refiere, ha sido distinguida con el Premio Nacional de Literatura Dramática (2018), el Premio Lope de Vega (2013), el premio HOLA de Nueva York (2010), el premio Chivas Telón (2007) y el premio Hogar Sur de Comedias (1998).

\section{La trayectoria dramática de Yolanda García Serrano}

En el ya mencionado trabajo de Cristina Santolaria, esta hacía hincapié en otra característica de la autora que, a su juicio y junto a su timidez, pudiera explicar la invisibilidad en la que ha vivido.

"No ha mostrado excesivo interés en que sus textos sean publicados, lo que provoca que, salvo quien es muy asiduo al devenir de la escena (principalmente madrileña), desconozca su escritura, casi única base de los estudios realizados desde el ámbito universitario y de la investigación". [...] La pérdida de los textos iniciales de su trayectoria, el desconocimiento del número de obras breves escritas, son algunas muestras de esa actitud que venimos señalando" [Santolaria 2020].

En efecto, la trayectoria teatral de esta autora y directora hay que escribirla en mayor medida a través de sus puestas en escena que de sus publicaciones, muy reducidas en comparación con la descomunal nómina compuesta por sus estrenos. García Serrano se formó con una figura fundamental para el denominado teatro alternativo madrileño de los años ochenta, Ángel Ruggiero. ${ }^{5}$ Tam-

\footnotetext{
Fuente: Academia de las Artes y las Ciencias Cinematográficas de España.

5 Ángel Ruggiero (Buenos Aires 1946 - Madrid 1992) exiliado político argentino. Fue director de teatro, pedagogo, investigador, fundador del Centro de Investigación teatral la Cuarta Pared y precursor del Movimiento de Teatro Alternativo en España. La revista Don Galán, del Centro de Documentación de las Artes Escénicas y la Música, publicó en 2019 un artículo sobre su obra y legado titulado Estética y ética moral del Teatro de Ángel Ruggiero, escrito por Nieves García Molina.
}

bién estudió con Jorge Eines. Poco después, en 1984, complementa su formación dentro del recién creado Centro Nacional de Nuevas Tendencias Escénicas (INAEM), donde tuvo por profesores a tres autores de referencia para el teatro español contemporáneo, José Luis Alonso de Santos, Fermín Cabal y Jesús Campos. A este último le reconoce ella como uno de sus fundamentales maestros (CDAEM, 2019) .

En 1983 realiza su primer estreno, un espectáculo infantil titulado Bisú, si venció o perdió, lo averiguas tú en un escenario al aire libre durante las fiestas de Aluche. En 1984 llega un nuevo estreno, en esta ocasión su obra se titula Cómo me gusta llamarte Ángel, una comedia sobre relaciones personales representada en diferentes centros culturales de Madrid y dirigida por Javier García Yagüe. También en 1984 se estrena otro texto suyo en el Centro Cultural de la Villa de Madrid (hoy teatro Fernán Gómez), dentro de un espectáculo conjunto titulado No hay función por defunción, humor negro en estado puro sobre el más allá en un montaje dirigido por Javier García Yagüe. En 1985, estrena su texto breve La llamada es del todo inadecuada, dentro del espectáculo Las tres gracias, parodia sobre el hombre contemporáneo compuesta por tres textos dirigidos por sus respectivos autores ${ }^{7}$. Jesús Campos se encargó de conferirle unidad al espectáculo, exhibido en el Círculo de Bellas Artes.

El diario El País recoge otro estreno suyo en 1986, Hasta en la oscuridad ${ }^{8}$, durante la Segunda Semana del Erotismo en el Centro Cultural de la Villa de Madrid. En 1987, vuelve a estrenar en ese mismo teatro, esta vez bajo su dirección y en solitario como autora, su texto largo La verdad después de la sonrisa, protagonizado por tres amigos delincuentes con problemas de relaciones sociales en un acercamiento al mundo del desarraigo a través del humor ácido. En 1998, estrena en el Puerto de Santa María ¡Qué asco de amor!, coproducida por la Fundación Muñoz Seca, que habilitó un espacio de novecientas sillas para el estreno y que previamente le había otorgado a la obra el Premio Hogar Sur de Comedias. En 2006 tiene lugar su siguiente estreno en el Teatro Maravillas de Madrid, con dirección de Tamzin Townsed, el de su texto Dónde pongo la cabeza, en el que aborda la lacra de los malos tratos desde el humor negro.

En 2008 estrena y dirige ella misma en el Teatro IATI de Nueva York su texto Good sex, good day, que sería estrenado en España en 2011 en el Teatro Arenal, traducido por Lo que ellos ignoran de ellas, en el que las protagonistas son tres mujeres que narran en clave cómica cómo fue su primera experiencia sexual. También en Nueva York estrena y dirige en el Baruch Performing Arts Center de New York en 2010 su obra Ser o no Cer... vantes ${ }^{9}$, escrita en colaboración con Salvador Toscano y cuyo argumento se centra en una conferencia magistral que imparte un estudioso empeñado en demostrar que

\footnotetext{
Fuente: entrevista del CDAEM de la periodista Esther Montero.

En Las tres gracias, además de García Serrano, participaron José Manuel Arias y Luis Araújo.

Fuente: El país, 3 de julio de 1986.

9 La obra consiguió tres premios HOLA (Hispanic Organization of Latin Actors). FUENTE: Fundación SGAE. www.fundacionsgae.org. Autores. Yolanda García Serrano.
} 
Cervantes y Shakespeare fueron la misma persona. Para apoyar su argumentación, expone y compara textos de ambos autores frente a un auditorio y dos periodistas que le refutan.

En 2011 estrena en la Sala Insular de Teatro de las Palmas de Gran Canaria su texto Ponte en lo peor, dirigido por Quino Falero, en el que venganza, traición, sexo y muerte se entrecruzan en una disparatada comedia. En 2016, en la sala Mirador de Madrid, estrena su obra ;Corre! En 2019 estrena en la sala El mirlo Blanco ${ }^{10}$ Halma, un encargo del Centro Dramático Nacional en el que recrea la vida de la escritora Halma Angélico, única mujer que consiguió estrenar en los teatros madrileños durante la Guerra Civil, feminista y anarquista acusada de contrarrevolucionaria por sus propios compañeros y represaliada después por el Franquismo.

\section{Montajes en colaboración y piezas breves}

Una constante en la trayectoria de García Serrano ha sido la de escribir y montar espectáculos en colaboración con otros dramaturgos. En el apartado anterior mencionábamos tres ejemplos de esa práctica de sus primeros tiempos. A esos títulos se les han ido sumando continuamente otros nuevos. El primero de ellos es Criaturas, estrenado en 1998 en el Teatro Poliorama de Barcelona y reestrenado en 1999 en el Teatro Lara de Madrid y en el que la participación de García Serrano cristalizó en el monólogo de una niña que en un juego de trabalenguas habla con sus padres separados y las consecutivas parejas de estos en una demoledora crítica al desafecto. Otro ejemplo es Amor y otros pecados, estrenado en el Teatro Amaya de Madrid en febrero de 2007 y para el que García Serrano escribió una pieza protagonizada por una encendida María Magdalena enamorada de Jesús de Nazaret.

También es un ejemplo de estas colaboraciones El manual de la buena esposa, estrenada en el Teatro Lara de Madrid en 2012, una parodia sobre mujeres ejemplares del franquismo en la que abordó la censura y otros males de la dictadura infringidos a las féminas; igual que lo son Alegrías, las justas, estrenada en 2012 en el Teatro Alfil de Madrid y en la que se recrea una hilarante conversación entre los cuadros de La maja desnuda y La Mona Lisa; Malas, estrenada en octubre de 2014 en la Sala El Bar, de Miami; Tamaño familiar, estrenada el 6 de febrero de 2015 en el Teatro Palacio Valdés de Avilés y cuya temática se centra en las relaciones familiares; Uniformadas, estrenada en 2016 en el teatro Guiniguada de Las Palmas de Gran Canaria y protagonizada por diferentes personajes femeninos que utilizan uniformes en su trabajo; Hablar por hablar, adaptación teatral del mítico programa radiofónico de la Cadena SER estrenada el 12 de enero de 2018 en el Teatro Bellas Artes de Madrid y Cuidados intensivos, que con el trasfondo de

10 La sala "El mirlo blanco", creada en 2012 por el CDN dentro del teatro Valle Inclán, recibió ese nombre como homenaje al teatro de cámara El Mirlo Blanco, creado en 1923 por Ricardo Baroja y su esposa en su propio domicilio. Allí leyeron y representaron sus obras Cipriano Rivas Cherif, Manuel Azaña, Valle-Inclán, Pío Baroja y otros dramaturgos. la enfermería como temática, bosquejaba la relación de tres hermanas y que fue estrenada en los Teatros Luchana en 2019.

En estas piezas, todas de género cómico, colaboró a propuesta de teatros y productores junto a autores como Juan Carlos Rubio, Miguel del Arco, Alfredo Sanzol, Félix Sabroso, Ignacio Del Moral, Juan Cabestany... El último de sus estrenos en colaboración ha sido El mueble (escrita junto a Juan Carlos Rubio), que vio la luz en el Teatro Lope de Vega de Sevilla en 2020 bajo la dirección del propio Juan Carlos Rubio y que, actualmente, se encuentra en gira. Esta pieza disecciona la salud emocional de una pareja que entra en crisis mientras monta un mueble comprado en IKEA.

A este listado de estrenos se unen otros basados en su teatro breve o microteatro. Un ejemplo de ellos es Asomados, protagonizado por un joven colgado de una cornisa que habla con su novia, a la que amenaza con tirarse al vacío si ella rompe la relación sentimental que los une. La obra vio la luz en 2008 en la sala "Microteatro por dinero", espacio en el que también estrenó en 2011 La novia tiene un síncope, en 2014 La novia de nuestro hijo no es nuestra hija y en 2017 Mi voto es un gozo, que aborda en clave de humor el enfrentamiento entre una sufragista española y su conservador marido. El formato de la lectura teatralizada también ha recreado en diferentes escenarios los textos de esta autora, títulos numerosos que no acogeremos en esta relación que destinamos exclusivamente a montajes completos y de carácter profesional. Aunque sí mencionaremos, como muestra de esa práctica, su texto breve Parapeto, comedia que ridiculizaba al entonces presidente de los Estados Unidos Donald Trump, en el entorno de una historia de amor entre dos hombres y periodismo sensacionalista. El texto participó en el I Torneo de Dramaturgia del Teatro Español en 2017, quedando la autora finalista del certamen, que ganó Ignacio del Moral.

\section{Cultivadora del género cómico}

Para iniciar una tarea de aproximación crítica a la obra de Yolanda García Serrano, acudimos de nuevo a Cristina Santolaria, que en su trabajo referido a esta autora analizaba la altura literaria de su teatro, que en su opinión utiliza el humor como fórmula para abordar temas duros y dolorosos con una mirada crítica revestida de aparente banalidad. Disertaba al mismo tiempo Santolaria sobre el menosprecio que sufre la comedia por parte de la crítica en España, afirmando que el hecho de haber dedicado García Serrano sus esfuerzos al género cómico, también podía explicar la reiterada falta de atención en torno a su obra.

La dificultad que entraña un género como la comedia, con escasos eslabones en el siglo XX, es inversamente proporcional al aprecio que por ella sienten los especialistas teatrales, quienes casi la consideran "obra menor", y ello sin valorar la carga crítica que puede conllevar el humor, como es el caso de García Serrano. [...] Me atrevería a apuntar un motivo más 
a la escasa atención por parte de los estudiosos hacia la obra de García Serrano y este puede proceder de ciertos prejuicios hacia las obras producidas por empresarios teatrales a los que se les ha etiquetado de "comerciales", quienes trabajan con directores que han probado su eficacia en la comedia o con repartos muy reconocidos por la televisión [Santolaria 2020].

Finalizaba esta investigadora sus argumentos añadiendo que el hecho de que un espectáculo logre captar la atención de públicos amplios no es en forma alguna sinónimo de escasa calidad o falta de compromiso con la realidad circundante, y que si un espectáculo "está bien", hay que reconocerlo de modo independiente del prestigio supuestamente "cultural" de los equipos que lo sustentan. A pesar de que, a día de hoy, Yolanda García Serrano no ha recibido suficiente atención por parte de la crítica científica y ningún artículo individual de estas características dedicado a su obra, pueden encontrarse menciones sobre su trabajo en algunos artículos genéricos sobre teatro español. Francisco Gutiérrez Carbajo, realizó un breve análisis de la obra de la autora Qué asco de amor, que presenta a tres amigas que se enfrentan al matrimonio de formas diversas y que encuentran en la amistad el equilibrio que las sustenta. En él, Gutiérrez Carbajo reparaba en la técnica teatral de la dramaturga, la desconstrucción que se manifestaba en la antítesis y contradicción de los tres personajes presentes respecto de los ausentes, sus parejas, de los que se habla, pero a quienes no se les da la oportunidad de expresarse. También hacía alusión al empleo del elemento humorístico en el texto.

La obra de García Serrano cuenta con indudables elementos lúdicos, como en los relatos de las experiencias sexuales, pero nunca se llega a construir un discurso enteramente humorístico. Cuando transcurre por los derroteros del humor o de la frivolidad, aparece un problema, una frustración, un lamento, que inclina la balanza hacia la emoción, y como sostenía Bergson, siguiendo a Nietzsche, cuando entra en escena la emotividad, desaparece lo risible [Gutiérrez Carbajo 2010: 133].

Este mismo investigador, a propósito de la pieza breve de García Serrano Aparta de mi este cáliz y también en la introducción genérica realizada para un libro antológico, decía:

Inserta su obra en la leyenda de Judas que, como comentó Vladimir Propp, cuenta entre sus antecedentes el de Edipo, incorpora variantes como la de San Julián, transita por la Gesta Romanorum y por otros textos medievales hasta llegar el relato de Flaubert, La leyenda de San Julián el hospitalario. Hay referencias a otros personajes, como Magdalena, Pilatos o a Ben-Hur [Gutiérrez Carbajo 2016: 30].

Francisca Vilches de Frutos dedicó su atención al monólogo de García Serrano 21 preguntas en la introducción a un volumen colectivo sobre malos tratos en el que quedó insertada esta pieza, explicando que la autora realizaba "una síntesis breve pero incisiva de los mecanismos empleados por los hombres para controlar a sus parejas y las consecuencias de su subversión, resumidas en una frase lapidaria: Y esa noche me fue imposible acabar el libro" [Vilches de Frutos 2017: 6].

Ana María Díaz Marcos, también en una introducción genérica a una antología teatral en la que participaba García Serrano con su pieza breve Entrevista atravesada, se refirió al teatro de esta autora como un peculiar testimonio de cómo la violencia define multitud de interacciones entre los seres humanos, replicándose a diferentes niveles. Las relaciones de poder en su teatro, añadía Díaz Marcos, se reafirman desde la violencia y la reproducen constantemente para apuntalar y mantener un sistema asimétrico y desigual: el orden de la competición y la explotación.

Nos presenta a una jefa llevando a cabo entrevistas para su empresa, muy cómoda con la desigualdad y las jerarquías que le permiten ser grosera con la aspirante al puesto, a quien insiste en humillar y empequeñecer al tiempo que refuerza su posición. [...] Después de agotar una dialéctica que insistía en descartar los méritos de la aspirante y poner en juicio su profesionalidad y aptitud para el puesto, la jefa se adentra en su vida familiar, a través de un excelente ejercicio de acoso verbal que ilustra las dificultades añadidas de las mujeres en el mercado laboral [Díaz Marcos 2018: 80].

En el prólogo primero a la edición de ¡Corre!, firmado por Verónica Forqué, la actriz califica la pieza de emocionante. "Cuando lees o ves la obra, y yo he tenido la suerte de verla en el teatro, se te encoge el corazón y estás deseando que acabe bien." [Forqué 2017: 9] El productor, guionista y director de cine Joaquín Oristrell, en el prólogo segundo de ¡Corre!, describía a García Serrano como escritora directa, sincera, ácida, honesta y comprometida; una personalidad que no atiende a modas ni tendencias y casi siempre habla de mujeres que cuestionan su propia condición. "En ;Corre!, -a través de tensas escenas que son como rounds- dos personajes corren en direcciones distintas buscando una salida" [Oristrell 2017: 11].

Lourdes Bueno analizó la obra Shakespeare nunca estuvo aquí en uno de sus artículos genéricos sobre teatro español, haciendo hincapié en el fuerte carácter de la protagonista femenina: "Una mujer nada convencional, decidida y muy ingeniosa, que no duda en llevar hasta el límite sus audaces ideas para conseguir sus propósitos" [Bueno 2019: 107]. Otro prólogo que destaca la altura dramática de García Serrano es el de Halma, en el que la bisnieta de la protagonista de esta pieza biográfica, Teresa Peydro Clar, reconoce el esfuerzo de la dramaturga por reivindicar la figura de Halma Angélico, "demasiado importante como para ser despreciada". [Peydro Clar 2019: 7] Ana María Díaz Marcos, autora del prólogo de la edición inglesa de Iceberg, escribe a propósito de la obra que es una vibrante y alegre historia que obra la magia de transportar a la audiencia a lo que debería ha- 
ber sido una noche memorable en el Titanic, al presentar una historia que entrelaza aventuras y negocios sucios junto al enredo y en engaño. [Díaz Marcos 2019: 65]

Entre la prensa dedicada a los estrenos encontramos muchas más referencias a esta autora que en el mundo de la investigación. Bastantes críticos han apreciado la calidad literaria de su teatro. Destacamos solamente dos de esas intervenciones, el comentario que, a propósito de La llamada es del todo inadecuada (inserta en el espectáculo Las tres gracias y protagonizada por una aterrorizada mujer que recibe la llamada de un perro al que confunde con su exmarido) realizó Juanjo Guerenabarrena en la revista El Público, calificándola de "Ionesco con gorro de baño" [Guerenaberrena 1986: 25]. Sobre el mismo espectáculo escribió Eduardo Haro Tecglen "La lección de dramaturgia que se desprende es si se encierra un trozo de realidad en un marco insólito, con otra luz, con otro contexto, se transforma inmediatamente en magia teatral" [Haro Tecglen 1986].

\section{El teatro editado de Yolanda García Serrano}

Frente al despliegue de estrenos de la autora, aparece la sucinta relación de sus publicaciones teatrales, compuesta por doce textos breves editados mayoritariamente por la asociación de autores de teatro de España en el entorno de actividades de promoción del teatro español, dos textos largos, ¡Corre! y Halma, una obra larga publicada en inglés, Iceberg, un texto largo editado por la Fundación Autor, ¡Qué asco de amor!, y un texto escrito en colaboración con Juan Carlos Rubio, Shakespeare nunca estuvo aquí, por el que ambos obtuvieron el premio Lope de Vega de Teatro en 2013.

Desde el punto de vista cronológico, la primera publicación de esta autora es iQué asco de amor! (2002), protagonizada por tres amigas y cuyo argumento se va desarrollando a lo largo de las bodas de cada una de ellas, coincidentes con cada uno de los tres actos en los que se divide. De estructura clásica, predomina en ella el acentuado conflicto entre el querer y el poder.

En el monólogo breve Bocata de calamares (2008) el protagonista es un joven de bajo estrato social que mata a un desconocido accidentalmente; en Reciclaje (2011) una pareja obsesionada con el aprovechamiento de los residuos comparte sus manías con el público en un juego de ruptura de la cuarta pared de apenas unas páginas; en La novia tiene un síncope (2012), otra obra breve, la estructura es compleja y se perfila en varios planos espacio-temporales convergentes. Una mujer es secuestrada el día de su boda por el mejor amigo de su novio. El propio secuestrador relata lo sucedido una y otra vez de forma incompleta, añadiendo en cada nuevo relato un detalle que va completando la historia, hasta hacernos comprender que el secuestrador mató a su víctima y después se suicidó, y que el personaje nos habla desde un intangible más allá que añade a la complejidad estructural un nuevo plano espacio-temporal.

La quinta obra publicada por García Serrano lleva por título La novia de nuestro hijo no es nuestra hija (2013), pieza breve en la que un joven hijo pide ayuda a sus padres para localizar a su novia, a la que no consigue encontrar. Se descubre finalmente que el matrimonio, movido por los celos, ha matado a la chica y están a punto de enterrarla. Nuevamente trabaja la escritora con la complejidad estructural. En su sexta publicación, también breve, iEsto es la guerra! (2014), dos mujeres batallan en primera línea de fuego, recibiendo de manera permanente llamadas de sus maridos que necesitan saber dónde están los uniformes de los niños o recibir instrucciones para poner la lavadora, en una acervada crítica sobre la condición femenina.

La pieza breve Media cebolla y un limón (2015), dedica su atención a un limón y media cebolla abandonados en un frigorífico por los dueños de la casa. El humor sirve de piedra angular para una disquisición de gran calado existencial sobre la vida y la muerte de estos infelices seres, símbolo de los desfavorecidos de la sociedad al compararse con el cordero y las gambas, a quienes sus propietarios no abandonaron. Mari Carmen (2016), aborda la temática de los enfrentamientos familiares. Dos cuñadas discuten porque una de ellas pretende llamar Mari Carmen a su hija, que nacerá en breve, nombre que la otra, que ni siquiera está embarazada, eligió para la suya. En Aparta de mí ese cáliz (2016), también breve, García Serrano utiliza la ironía para relatar las relaciones entre un Jesucristo que no desea ser crucificado y un Judas que se niega a ocupar el puesto de su maestro en la cruz, por más que este se lo sugiera, ruegue y finalmente ordene. En 2016 aparece una nueva publicación larga, escrita junto a Juan Carlos Rubio, Shakespeare nunca estuvo aquí, comedia sobre la suplantación de la identidad del genio inglés por parte de otro dramaturgo.

En Empleo juvenil (2017), en apenas unas páginas, se repasa a ritmo trepidante el proceso de entrevista de trabajo al que se somete un joven. Descubrimos finalmente que la entrevistadora es realmente su madre, trastornada por sus desmedidas ganas de insertar a su hijo en el mercado laboral. Otra publicación es 21 de junio (2017) en la que una parturienta a punto de dar a luz pide dinero en la calle para un taxi, y el brevísimo monólogo 21 preguntas (2017) cuya temática son los malos tratos y que posee una original estructura: está compuesto por cortantes frases, las preguntas que un hombre le hace a su mujer antes de asesinarla. También el 2017 ven la luz las obras largas Iceberg, comedia sobre dos ladrones infiltrados en el Titanic, y ;Corre!, que protagonizan dos hermanos.

En Entrevista atravesada (2018), dos mujeres se enfrentan dialécticamente en una entrevista de trabajo. Entrevistadora y aspirante, cruzan sus dotes lingüísticas en esta pieza breve que, desde el humor, realiza una dura crítica a los abusos y la discriminación femenina en el mundo laboral. Halma (2019), obra larga ya mencionada, es la última publicación de esta autora.

Aparecen características comunes en estos textos, que cimentan las peculiaridades de un estilo propio y sólido en García Serrano. El elemento sorpresa atraviesa su teatro (La novia tiene un síncope, La novia de nuestro hijo no es nuestra hija y Empleo juvenil), también la reflexión sobre el oficio de escritor encarnada en el metateatro (Ser o no Cer... vantes, Shakespeare nunca 
estuvo aquí o Halma), la desigualdad social y el desarraigo (Bocata de calamares, Iceberg, Media cebolla y un limón) y las difíciles relaciones familiares (Mari Carmen y Empleo juvenil). Pero el gran tema de García Serrano es la condición femenina, la desigualdad sufrida en todos y cada uno de los ámbitos por las mujeres y la complicidad que emplean como arma para ayudarse entre sí, condición femenina que alcanza su máxima cima argumental en su preocupación por los malos tratos, que ha explorado a lo largo de toda su trayectoria: 21 preguntas y Dónde pongo la cabeza ilustran esta constante.

También es recurrente en ocasiones en la autora la experimentación con estructuras que cruzan planos convergentes y divergentes como recurso argumental, y la capacidad para imprimirle ritmo a sus tramas. Otra característica destacada de su teatro es la pureza y contundencia del conflicto que presenta y la habilidad para el diálogo de la que ella dota a sus personajes para abocarlos de manera directa a un enfrentamiento que solo puede condenarlos al triunfo o al fracaso.

\section{5. ¡Corre! Estrategias discursivas en el texto}

¿Corre!, considerada la obra cumbre de García Serrano, abunda en dos temas comunes en su teatro, las relaciones familiares y el desarraigo, pero desde una óptica radicalmente distinta. Los protagonistas son Kico, de treinta y tres años, y Emma, su hermana mayor. La acción dramática se desarrolla mayoritariamente en la cárcel en la que él cumple condena. Las acotaciones iniciales de la pieza que nos describen a los personajes dicen: "KICO. Ha pasado media vida en centros penitenciarios. Parece que lo suyo no tiene solución. ¿O sí? EMMA. Profesora de música sufridora a tiempo completo. Su hermano la trae por la calle de la amargura." [García Serrano 2017: 15]

La obra obtuvo el Premio Nacional de Literatura Dramática en 2018. El jurado que concedió el galardón destacó "su gran fuerza dramática, su emotividad, su creación de personajes que retratan la eterna batalla entre los seres y su entorno", puntualizando también que se trataba "de una literatura dramática puente entre las formas más tradicionales y las formas más nuevas y, principalmente, por su resolución del difícil problema de la evolución temporal de la historia"11.

En el segundo prólogo a su edición, afirma Joaquín Oristrell que está "escrita a puñetazos, con las tripas, escupida y llorada" [Oristrell 2017: 11] en alusión a que se inspira en un suceso autobiográfico para la autora. La conmoción producida por ese acontecimiento, desplazó en ella lo que Barthes denomina "logosfera", el hábitat que recubre al artista y que solo puede ser trasladado "al sacudir la masa equilibrada de las palabras, rasgar la envoltura, deshacer el orden de las frases, romper la estructura del lenguaje" [Barthes 2009: 362]. El resultado de esa sacudida fue una nueva manera de concebir el teatro por parte de Yolanda García Serrano, un auténtico antes y después. De hecho, ¡Corre! es el primer drama escrito por la autora.

11 Acta del jurado del Premio Nacional de Literatura Dramática, edición 2018.
La pieza está en las antípodas de una estructura clásica al uso, posee veinticinco escenas desarrolladas temporalmente en el periodo de un año y ocho espacios argumentales, con las dificultades que eso implica para su propia concepción textual y para cualquier intento de puesta en escena entendida, siguiendo a Kowzan [1992] como producto teatral comunicado en el espacio y en el tiempo. La gestación del texto fue lenta y complicada, y desde el primer momento, su autora supo que ella misma la llevaría a escena, bosquejando en su cabeza cómo articularía la secuenciación temporal y espacial y cómo segmentar los movimientos de los protagonistas ${ }^{12}$. Carmen Bobes asegura que los teóricos del teatro "suelen interrelacionar los conceptos de espacio-tiempo y movimiento" [Bobes 1997: 24]. Esa óptica de estudio se adapta a la perfección al proceso de desarrollo y materialización de ;Corre!, ya que estos tres elementos se encuentran imbricados por completo en ella.

Otro elemento fundamental en la obra son las acotaciones, "que designan el contexto de la comunicación, determinan una pragmática, es decir las condiciones concretas del uso de la palabra" [Ubersfeld 1989: 17]. Es significativo el uso de las didascalias en ;Corre!, con una fuerte presencia de la función expresiva en el empleo del lenguaje que matiza la información recibida a través del empleo de la función referencial establecida por Jakobson y redefinida por Ingarden (1997) para la especificidad teatral, recurso dramático del que se sirve la autora para significar los estados emocionales y sensaciones que deben ir unidos a la situación dramática. Lenguaje de eficacia, que para el texto dramático “constituye el único material" [Veltrusky 1990: 15]. Un ejemplo de la efectividad de esa táctica lo encontramos en la didascalia que da comienzo a la obra.

Emma parece recibir una descarga. Se lleva las manos a los ojos. Resopla intentando recuperarse de la ansiedad que la embarga mientras espera impaciente a que llegue la persona con la que ha concertado una visita. [...] Está a punto de escapársele una lágrima, pero se controla y se enfrenta a Kico con un gesto de rabia y dolor [García Serrano 2017: 17-18].

El conflicto de esta pieza se nos presenta en la primera escena, Emma visita a su hermano en la cárcel para comunicarle que su madre ha fallecido y que los dos recibirán su herencia, la vivienda que constituía para ella su única posesión. Ambos deberán ponerse de acuerdo y dividir la propiedad, y eso significa que Emma y Kico tendrán que verse y tratar el uno con el otro durante un tiempo indeterminado. Pero Emma no quiere ver a Kico, que remueve en ella el antiguo dolor de saberle un fracasado, el perdedor de una difícil existencia que los dos compartieron desde niños y de la que ella, milagrosamente, salió indemne. Para Emma el nudo gordiano de su dolor se reconcentra en una pregunta: ¿por qué ella pudo salvarse y él no? Ese conflicto de carácter interno junto al segundo conflicto desarrollado "en un espacio

12 Fuente CDAEM (Ministerio de Cultura y Deporte.) 
físico, cultural determinado" [Ubersfeld 1989: 137], el reencuentro con su hermano en la cárcel, cimenta la acción dramática.

En ese primer encuentro ya emerge el carácter de los personajes. Kico desapareció hace tres años sin previo aviso. Su madre murió esperando recibir noticias suyas. Y de pronto, con ella ya fallecida, cuenta por carta que se encuentra en la cárcel. El choque de fuerzas antagónicas que constituyen las personalidades divergentes de los dos hermanos se mantiene en un estado de máxima tensión durante toda la obra. La visceralidad y la incapacidad para la más elemental planificación vital de Kico frente a la tenacidad, el sentido del esfuerzo y las aptitudes para la supervivencia de Emma. Almas complejas bosquejadas por certeros diálogos de gran efectividad y velocidad cargados de tensión, característica del teatro de García Serrano y una de las señas de identidad más palpables de su calidad dramática, que entroncan con la "performatividad" [Lozano y Peña-Marín y Abril 2018: 174] intrínseca a lo dramático.

Pivotando alrededor de los protagonistas, dos "personajes latentes" [García Barrientos 2003: 162], la madre de ambos como representación del pasado y el marido de Emma, encarnación del presente. Con su marido conversa Emma una y otra vez al regresar de sus visitas a la cárcel, sumida en una gran perturbación emocional, prometiéndole que no volverá jamás a esa prisión. Pero Emma regresará una y otra vez arrastrada por una contradictoria fuerza de succión y repulsión repetida en el tiempo y el espacio. "En cuanto estén los papeles y firmes, puedes volver a desaparecer, que no voy a buscarte", le lanza Emma a Kico [García Serrano 2017: 25], "No le volveré a ver. Dejaré el piso en manos de un abogado", confiesa Emma a su marido [García Serrano 2017: 27]. Pero las visitas de Emma se extienden durante un año.

El empleo de personajes latentes es un recurso de gran efectividad, ya que se encuentran situados en la encrucijada de todas las incertidumbres textuales y metodológicas [Ubersfeld 1989: 85] y le confieren al texto intensidad y ritmo. Las conversaciones de Emma con su marido y las de Kico con una asistente social, otro personaje latente (pp. 28-29), son fundamentales en la estrategia dramática, permiten hacer avanzar la trama y atrapar en tu totalidad las complejas aristas de la personalidad de estos seres, "el contexto formado por sus discursos" [Veltrusky 1990: 18]. Otros personajes latentes que potencian este efecto son dos compañeros de celda de Kico (pp. 59-60 y pp. 72-73), su entrenador (pp. 70-71) y un abogado que intermedia en la venta del inmueble (pp. 93-95).

Los espacios argumentales, numerosos, se agrupan en dos categorías, los recorridos por Emma y los recorridos por Kico. Emma transita por todos los enclaves (la celda de Kico, el gimnasio, la sala de visitas, la sala de vis a vis...) mientras su hermano jamás pisa los espacios propios de ella. Cada subgrupo de espacios está regido por propulsiones opuestas. Especial relevancia posee en el desarrollo de la trama el hogar de Emma, lugar en el que los demonios de la joven se desatan, atormentándola y obligándola a edificar una relación que no desea con su hermano, una intimidad que la aterroriza, un apego del que intenta zafarse infructuosamente. Recapacitar es justamente lo que menos desea Emma, rumiar sobre por qué y cómo sucedió aquello en el pasado o para qué sucedió. Pero su casa, como espada de Damocles, propicia su involuntaria reflexión y la obliga a comprender a Kico, a apegarse a su presencia, a desearla paulatinamente, a quererle.

Como temas principales predominan en el texto los mencionados al inicio del capítulo, la familia y el desarraigo; también la suerte, como elemento misterioso propiciado por el capricho, es recurrente en ella, simbolizando la fatalidad. Pero otros muchos circulan por la espina dorsal de este drama: la incapacidad para sobreponerse a las adversidades, el terror a conocerse a uno mismo, la difícil intersección entre las relaciones amorosas y las obligaciones familiares, el analfabetismo emocional, la necesidad de sondear el pasado y el deseo de autorrealización son algunos de ellos. Y, aglomerado entre todos, un tema en apariencia insignificante, pero lleno de entidad: el miedo a la vida. Ese miedo que a veces paraliza pero que en otras ocasiones gesta en nosotros la urgencia por escapar y que nos dice al oído: ¡corre!

\section{La eficacia comunicativa en la representación de ¡Corre!}

Una importante corriente de investigación considera que, por encima de todo, el teatro es un acto de comunicación que opera en distintos niveles e implica un número diverso de emisores y receptores, "una representación es un producto final altamente organizado." [Sarason 2002: 35] ¡Corre! se estrenó en marzo de 2016 en la Sala Mirador de Madrid. Teniendo en cuenta que, en el teatro, el espectáculo es el mensaje, o al menos, el mensaje principal [White 2012] la propuesta escénica fue de una extraordinaria eficacia; cosechó un gran éxito de público y mantuvo el cartel de localidades agotadas durante todas las representaciones. En 2018, se reestrenó en el Teatro Galileo ${ }^{13}$. En ambas ocasiones fue dirigido por la propia autora.

Asegura Manuel Vieites que, en determinadas circunstancias, el fracaso de un espectáculo se debe al hecho de no haberse sabido construir los procesos de comunicación que todo espectáculo debiera generar, replicar y mostrar, "ni la necesaria interacción entre los mismos, aunque en otras ocasiones el espectáculo fracase porque no se han sabido leer los conflictos que la obra presenta desde la óptica de la comunicación" [Vieites 2016: 1158]. Nada más lejos del caso que nos ocupa. La dirección de García Serrano aseguró que los matices de este profundo texto fueran aprehendidos en toda su dimensión para promover respuestas complejas en el público, potenciándose en la representación el contenido proposicional del discurso y su fuerza ilocutiva, [Searle 1980] base de toda actividad comunicativa.

"Todo espectáculo teatral presenta pues esa doble emisión por la cual expresión dramática (que da lugar al mundo dramático, o "MD”) y expresión teatral

13 La representación está disponible en la Teatroteca del CDAEM. 
(que da lugar a un mundo escénico o "ME") se superponen. El primero lo recrea el dramaturgo empírico con el texto secundario y los personajes en sus diálogos, y el segundo se configura mediante los procesos de escenificación" [Vieites 2008: 1163].

Partiendo del desafío-disyuntiva entre lo escénico y lo dramático planteado por Vieites, y que nos lleva a entender una representación teatral como algo desarrollado en un tiempo y un espacio, uno de los aciertos de la representación fue saber condensar en un único espacio escénico los múltiples espacios argumentales que albergaba la obra. Sobre un escenario sin separaciones convivían al mismo tiempo la cárcel, su sala de visitas, su sala de vis a vis, el gimnasio, el patio de la prisión, la sala reservada a encuentros entre técnicos y presos, la casa de Emma y un espacio neutro y polivalente. Cada uno de ellos estaba representado por un objeto de alto contenido simbólico: una litera para la celda de Kico, un banco de abdominales emulando un gimnasio, una mampara para evocar una sala... En ocasiones, los espacios cobraban vida a través de un cambio de luz, o de una diferente modulación en la voz empleando al máximo las posibilidades de los sistemas de signos identificados por Kowzan [1992]. Signos en definitiva ambiguos y polivalentes, "interpretables e interpretados" [Kowzan 1997: 159].

La compleja estructura de la obra requería el despliegue de imaginación y oficio que derrochó su directoraautora. Uno de los desafíos en ¡Corre!, dividida en veinticinco escenas, era hacer percibir a los espectadores el trascurso del tiempo. La opción que ella eligió fue una sucesión sin solución de continuidad de los espacios argumentales que generaban la mutación temporal, sin cambios escenográficos ni interrupción alguna; recurso que posibilitaba mantener el ritmo.

Pero a la dificultad de representar veinticinco escenas acontecidas en el intervalo argumental de un año en una hora y media de tiempo cronológico (duración del espectáculo) se unió una todavía más difícil de sortear para un director escénico. Y todo ello, debido a que, en un despliegue de innovación estructural, García Serrano autora hacía cohabitar en la misma escena media docena de diferentes espacios de la representación con sus correspondientes argumentos, tiempos y personajes protagonistas que operaban como subescenas mediante perfectos juegos matemáticos de elipsis. García Serrano directora lo solventó con una lluvia constante de acción dramática en la que unas y otras situaciones se encadenaban, sucedían y conseguían ofrecer al público el efecto de que lo que acontecía no era consecutivo, sino simultáneo.
Conviene tener en cuenta en el teatro, puntualiza Kowzan, los estados afectivos, las emociones como signos naturales y también las sensaciones o sentimientos como signos artificiales que dan sentido a los personajes y culminan el proceso de la comunicación. "Teniendo en cuenta ambos criterios, distinguiremos, por un lado, el estado afectivo del emisor de un signo, así como el estado afectivo del receptor y por otra parte, la emoción expresada por el emisor, emoción percibida (e interpretada como tal) por el receptor [Kowzan 1997: 239].

Este binomio que resume cabalmente el paso de sentido imprescindible para la comunicación, consiguió completarse en el montaje de ¡Corre! De manera gradual el espectador asiste al proceso de anagnórisis de experimenta Emma, su tránsito de la ignorancia al conocimiento, el descubrimiento de que las aciagas condiciones de vida en las que desarrolla su hermano su existencia, no son fruto de la casualidad, sino de los malos tratos que su madre ejerció contra aquel niño que vivió bajo el mismo techo que ella sin que ella alcanzara a detectar aquel espanto para paliarlo, para frenarlo. Esa certeza remueve al personaje colocándolo al borde de un abismo que el espectador experimenta como propio. La violencia que Emma ejerce sobre Kico en los momentos de máxima tensión (escena 20) produce revulsión en el espectador. Se palpa el miedo de Emma a imitar viciados comportamientos heredados, a reproducir esquemas. Se huele su pánico a la verdad, a la constatación que puede deslumbrarla y abocarla a una sima abisal.

Como espectadores, nos esperanzamos junto a Kico cuando anuncia que quiere redimirse y en la tercera escena le pide a la asistente social un cambio de módulo; nos indignamos en la escena siete cuando Emma se enfrenta a su marido que le prohíbe ver a Kico y le espeta que un hermano no es una enfermedad contagiosa de la que se deba huir, sufrimos junto a la Emma que declara que un hermano no puede romperse en trocitos y tirarse a la basura; nos sentimos impotentes junto a Kico, que en la escena dieciocho, en la celda de aislamiento, se golpea la cabeza contra la pared, consciente de que es incapaz de no equivocarse, de no elegir mal; nos sobrecogemos cuando el Kico de la escena veinticuatro cae el suelo sin conocimiento, ya cadáver. Y nos quedamos en blanco en la escena veinticinco cuando Emma, agitada por una crisis existencial, se marcha de su casa anunciando un largo viaje tras el que se intuye un cambio de vida radical. Y suscribimos su decisión. Y la aplaudimos. Y nos vamos con ella de viaje. Y de pronto descubrimos que la montaña rusa de emociones que ese espectáculo está haciéndonos atravesar debe ser ese estado emocional sobrecogedor y mágico que los griegos denominaban catarsis.

\section{Referencias bibliográficas}

Bartes, Roland. (2009): Escritos sobre el teatro. Barcelona, Paidós.

Bobes, Carmen (1997): Teoría del teatro. Madrid, Arco Libros.

Bueno, Lourdes (2019): “Autoras creando autores: escritores como personajes en obras de autoría femenina". ESTRENO. Actas V Congreso Estreno: 104-115.

Díaz Marcos, Ana María (2018): Escenarios de crisis. Dramaturgas españolas en el nuevo milenio. Sevilla, Benilde.

- (2019) "A note of Yolanda García Serrano and Iceberg", en Praga, de Javier de Dios, Iceberg, de Yolanda García Serrano. New Jersey, Estreno Contemporary Plays $n^{\circ} 40$ 
García, Nieves (2019): "Estética y ética moral del Teatro de Ángel Ruggiero". Don Galán n 9, CDAEM.

García Barrientos, José Luis (2003): Cómo se comenta una obra de teatro. Madrid, Síntesis.

White Gareth (2012): “On Inmersive Theatre”. Theatre Research International 37 (3): 221-235.

García Serrano, Yolanda (2002): Qué asco de amor. Madrid, Fundación Autor.

- (2008): Bocata de calamares. En Maratón de Monólogos 2008. Madrid, AAT.

- (2011): Reciclaje. En El tamaño no importa. Textos breves de aqui y de ahora. Madrid, AAT.

- (2012): La novia tiene un síncope. En El tamaño no importa. Textos breves de aquí y de ahora. Madrid, AAT.

- (2013): La novia de nuestro hijo no es nuestra hija. En El tamaño no importa. Textos breves de aqui y de ahora. Madrid, AAT.

- (2014): ¡Esto es la guerra! En El tamaño no importa. Textos breves de aquí y de ahora. Madrid, AAT.

- (2015): Media cebolla y un limón. En El tamaño no importa. Textos breves de aquí y de ahora. Madrid, AAT.

- (2016a): Mari Carmen. En El tamaño no importa. Textos breves de aquí y de ahora. Madrid, AAT.

- (2016b): Aparta de mí ese cáliz. En La paradoja del dramaturgo. Madrid, Esperpento: 147 - 155.

- (2016c): Shakespeare nunca estuvo aqui (escrita conjuntamente junto a Juan Carlos Rubio). Madrid, Antígona.

- (2017a): ¡Corre! Madrid: Ediciones Antígona.

- (2017b): Iceberg. ESTRENO. Collection of Contemporary Spanish Plays no 40. Junto a Praga, de Javier de Dios.

- (2017c): Empleo juvenil. En El tamaño no importa. Textos breves de aqui y de ahora. Madrid, AAT.

- (2017d): 21 de junio. Madrid: Revista Eñe, 2017, invierno.

- (2017e): 21 preguntas. En 50 voces contra el maltrato. ESTRENO. VOL. XLIII, No 2. OTOÑO 2017.

- (2018): Entrevista atravesada. En Escenarios de crisis: dramaturgas españolas en el nuevo milenio. Antología de Ana María Díaz Marcos (ed.). Sevilla, Benilde.

- (2019): Halma. Madrid: Ministerio de Cultura. Autores del CDN.

Guerenabarrena, Juanjo (1986): “Las tres gracias”. El Público n 29: 25-26.

Gutiérrez Carbajo, Francisco (2010): "La des(cons)trucción y el humor en el teatro español contemporáneo", en El teatro de humor en los inicios del siglo XXI, Romera J. (ed.). Madrid, Visor: 119-142.

- (2016). "Prólogo" a La paradoja del dramaturgo. Madrid: Esperpento: 7-41.

Haro Tecglen, Eduardo (1986): "El misterio de la dramaturgia”. El País, 4, 01, 1986. «Crítica | El misterio de la dramaturgia».

Ingarden, Roman (1997): "Las funciones del lenguaje en el teatro”. En Teoría del Teatro, Bobes, C. (ed.). Madrid: Arco Libros.

Hormigón, Juan Antonio (2000): Autoras en la Historia del Teatro Español (1975-2000), III. Madrid, ADE: 363.

Jakobson, Roman (1981): Lingüística y Poética. Madrid, Cátedra.

Kowzan, Tadeusz (1992): Literatura y espectáculo. Madrid, Taurus.

- (1992). Spectacle et signification. Québec, Les Éditions Balzac.

- (1997) El signo y el teatro. Madrid, Arco Libros.

Lozano, Jorge y Cristina Peña-Marín y Gonzalo Abril (2018): Análisis del discurso. Madrid, Cátedra.

Montero, Esther (2019): Entrevista a Yolanda García Serrano. Figuras, 4. CDAEM. En línea. https://www.youtube.com/ embed/ARiRURIHId0.

Oristrell, Joaquín (2017): “Con las tripas”. Prólogo a ¡Corre! Madrid, Antígona.

Peydro Clar, Teresa (2019): "Prólogo" a Halma. Madrid, Ministerio de Cultura.

Santolaria, Cristina (2020): "Una dramaturga peculiar, polifacética y desconocida: Yolanda García Serrano". En La Autoficción teatral. Las puertas del drama 53. Año 2020, $2^{\circ}$ semestre.

Sarason, Seymour B. (2002): La enseñanza como arte de representación. Buenos Aires, Amorrortu.

Searle, John (1980): Los actos del habla. Madrid, Çátedra.

Ubersfeld, Anne (1989): Semiótica teatral. Madrid-Murcia: Cátedra-Universidad de Murcia.

Veltrusky, Jirý (1990): El drama como literatura. Buenos Aires. GALERNA.

Vieites, Manuel (2016): “Teatro y Comunicación, un enfoque teórico”. En SIGNA 25, 2016: 1153-1178.

Vilches de Frutos, Francisca (2017): “Teatro y sociedad: un balance sobre la violencia de género en la escena española actual". En ESTRENO Vol. XLIII: 3-16.

White, Gareth. (2012): “On Inmersive Theatre”. Theatre Research International 37 (3): 221-235. 
